\title{
Health Informatics Education and Capacity Building in Eastern Cape Province, South Africa
}

\author{
P. J. Murray, H. J. Betts, G. Wright, N. V. Tshayingca-Mashiya \\ Centre for Health Informatics Research and Development (CHIRAD) and The University of Winchester, \\ Hampshire, England; Walter Sisulu University, Mthatha, Eastern Cape, South Africa
}

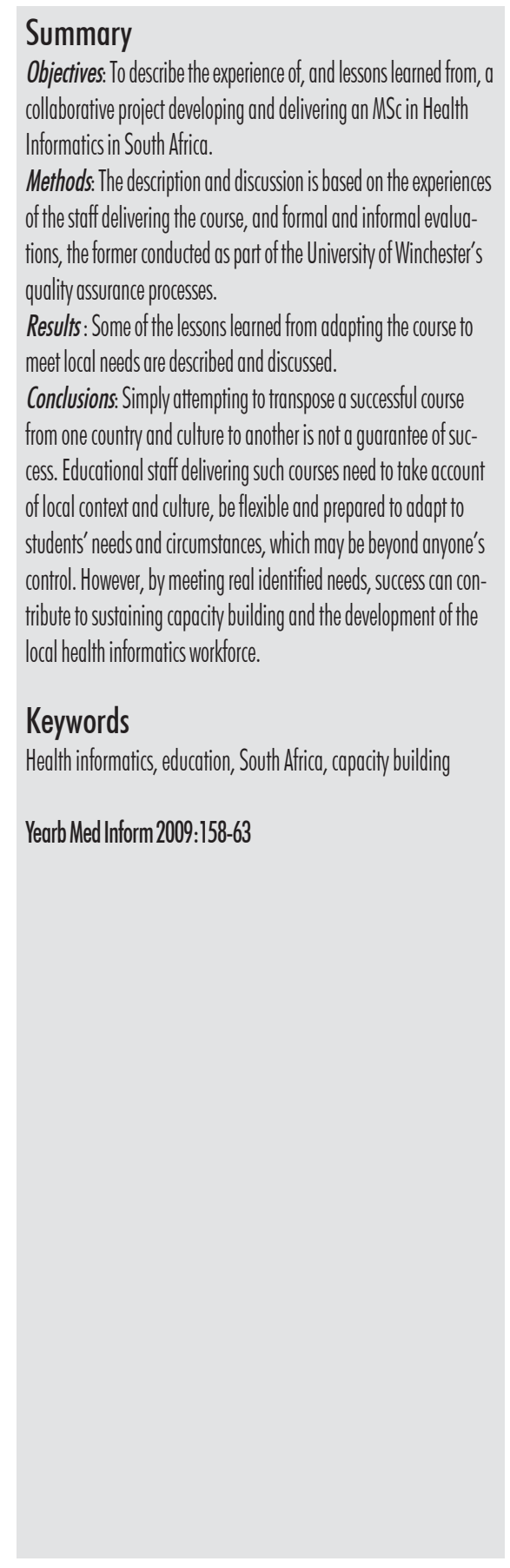

\section{Introduction}

This paper provides both a reflection on the experiences, and an overview of the issues, resulting from the development and delivery of a Master of Science (MSc) in Health Informatics course in Mthatha, Eastern Cape, South Africa. The course was part of wider initiatives to increase the ability of South Africa to be self sustaining in health informatics education and training, and was the result of collaboration between the South African Medical Research Council, the University of Winchester (UK), Walter Sisulu University (SA), Eastern Cape Department of Health (SA) and the Centre for Health Informatics Research and Development (CHIRAD) (UK).

Some background information on the development of health informatics in South Africa is provided, which sets the context for the course and other developments. A brief overview is given of the philosophy of the course, as it has been described in detail previously [1]. The focus of discussion is on the issues arising from delivering the course in a resource challenged country, and is based on the formal evaluation undertaken as part of the University of Winchester's quality assurance mechanism [2]. Perspectives are provided from both the educators involved in delivering the course and the students, all of whom worked, and continue to work, in South Africa in the health services, the higher education sector, and the provincial government. The lessons learned may have wider application to those considering such joint projects between developed and developing countries, although some issues may be country-specific.

\section{Background - The Need for Development of Health Informatics in South Africa}

South Africa has a population of 48 million, $46 \%$ of whom live in rural areas, has 11 official languages and administratively is divided into nine provinces. While it has one of the largest and most developed economies in Africa (with a GDP of US\$218 billion), it suffers from problems that directly and indirectly affect the health services. Among factors contributing to health problems are an official unemployment rate of $23 \%$ (unofficially over $42 \%$ ), and $50 \%$ of people living below the poverty line (with $11 \%$ living on less than US\$1 per day). South Africa also has a significant burden of direct health issues; AIDS is the leading cause of death, and HIV prevalence in people 15 years or older is $17 \%$, while under-5 child mortality is 58.3 per 1000 births, and average life expectancy is 42 years [3].

The Eastern Cape Province has a population of 6.3 million people and is the third most populous part of the country. Around $86 \%$ of the population are African/Black [4]. Walter Sisulu University and Mthatha, where the course was delivered, are situated in OR Tambo district, in the eastern part of the Eastern Cape, an area that has been declared a priority and focus area for government, as the area has been particularly affected by underdevelopment, poverty and unemployment [5]. One of the main objectives of the growth and development plan of the Eastern Cape Province is transformation of the pub- 
lic sector, including strengthening institutions of higher education to cater for the majority of the previously disadvantaged population. It was in line with this objective that the Department of Health Eastern Cape, together with Walter Sisulu University (previously Unitra, the University of Transkei) in collaboration with the University of Winchester and CHIRAD started an MSc Health Informatics in 2006 [6].

There is an urgent need for capacity building in health informatics and e-Health at all levels in the South African health system. In June 2007, South Africa launched its national electronic health record (EHR) strategy, which has considerable implications for education and training of health professionals [7]. Any increase in the use of health information systems (HIS) and information technology (IT) projects requires the government to increase both the quality and the quantity of education, training and research [6]. The technology skills demand in the health care sector, especially in countries such as South Africa, exceeds the supply, and it is well recognised that the effective use of information systems can be achieved if technology advances in health care are matched to the skills of the health professionals [8], as well as to the development of leadership support, including skills in the management of change [9]. At present, many health workers do not have any computer training, and those from rural schools may never have used a computer [3]. These professionals need training that will equip them to deal with the challenges that come with the implementation of health IT projects, both locally and nationally [6]. As the focus of this MSc included organisational and implementation issues $[1,10]$, it was well-suited to meeting local capacity building needs.

The development and local retention of skills and knowledge are also part of the wider needs for societal development. Access to knowledge and information during the days of apartheid was for the privileged minority
[11]. The transformation agenda of South Africa, as enshrined in the Reconstruction and Development Programme (RDP) [12], as well as the National Health Plan [13], have endeavoured to bring dignity to the majority of South Africans, underpinned by knowledge development, access to information and services, and general improvement in lifestyles. Better health information systems knowledge and practice can improve health services at all levels [14]. Since the 1994 elections, South Africa has worked to redress the imbalances of the past in terms of access to and distribution of resources [15], facilitated by the establishment of new state services, accounting structures and institutions [16].

The initiative described here is not the first within South Africa in education or health information systems; many other projects have originated both within South African institutions and through collaboration with external bodies, although few have targeted the more disadvantaged areas such as Eastern Cape. For example, the University of Oslo, in collaboration with University of Western Cape, has offered a health informatics course aimed at building capacity in informatics and catering for students from South Africa, Mozambique and other countries within the Southern African Development and Economic Community (SADEC) region [14]. The District Health Information System (DHIS), also originally developed by the University of Oslo, and including the Health Information Systems Program (HISP) is a widely used public health information system, based in free and open source (FOSS) applications for collecting and sharing aggregated data from health facilities and transmitting it to higher levels in the public health system $[3,17,18]$. Mars and Seebregts [3] provide an extensive discussion of issues pertinent to the wider development of health informatics and capacity building within South Africa, and provide many examples of other projects and courses.

\section{The Course Model and Delivery in Mthatha}

The development and delivery of the MSc in Health Informatics course in Mthatha was the result of collaboration between the South African Medical Research Council, the University of Winchester, Walter Sisulu University, and the Centre for Health Informatics Research and Development (CHIRAD). The initiative was also supported by the Eastern Cape Province Department of Health, which wanted to develop skills in information management among health professionals and those supporting the delivery of healthcare, so as to improve health care and service delivery in South Africa. The MSc in Health Informatics was seen as one part of a larger and longer-term initiative that also sought to develop a centre of excellence in health informatics in development, training and application in clinical practice for the province and South Africa, based at Walter Sisulu University (WSU). Significant funds have been invested to develop, over several years, a core of graduates and, in particular, health care professionals trained in health informatics at various skills levels in Eastern Cape and other provinces.

While the South African Medical Research Council (MRC) is not directly a teaching organisation, it is able to identify areas of need within the country, such as teaching in health informatics, and fund projects to help development. Eastern Cape Province is an under-served area in terms of health informatics capacity, and the concept of a course that "trains the trainers", which the development of a local cohort of health informatics graduates aims to do, made sense for the South African context. Due to the relative lack of existing health informatics expertise, especially in education and training, in South Africa, there was a need for external collaboration and input to start the capacity building process, which also provided an opportunity for South Africans to make contacts in health 
informatics outside the country. As the MRC has a Memorandum of Understanding with CHIRAD, which itself has a collaboration with the University of Winchester, a natural consortium arose. As one of those involved in the establishment of the venture has noted:

"to solve the challenge of informatics and its needs in a developing country like South Africa, there has been a need to take an advantage from IMIA, such as exchange of courseware and teacher resources, develop a source material within certain standards and send a number of people with potential to do Masters and Doctoral degrees" [6].

Since 1994, as part of the strategic development of its health services, South Africa has been developing 500 information officers. These are people with a health informatics role, in terms of gathering and analysing health information, and using it for planning purposes. They work in all hospitals, every health district, and at other levels. However, at sub district level and at the smaller hospitals in the public sector, there are no information officers, but there is recognition that they are needed. Some information officers are also required with Masters level qualifications, particularly at provincial and district government levels. Eastern Cape Province invested through funding support and through providing staff for the first cohort of MSc students.

The course model has been described previously in the IMIA Yearbook [1], but it is worth repeating some of the key components of the underlying model and the delivery mechanisms, as they are relevant to evaluation, both formal and informal, of the issues and success of delivering the course in a different context to that originally envisaged. The course is grounded in a view of health informatics as being concerned with the individual and group behaviour of health care personnel in their interaction with information and information technologies. It is an academic course giving strategic and clinical insights into the use of informatics, not a technician's course, although a module is included which addresses technical issues, in particular emerging technologies that might influence the delivery of healthcare and the use of healthcare information. Domains of health informatics include delivery of care and promotion of health, information management and technology and organisational settings of health care. Aarts, Peel and Wright have shown how the three domains interact, and this work contributed to the underpinning philosophy of this and other courses [10].

The MSc course is also designed to address issues such as the fundamental changes that are taking place in the practice of clinical work and in health care systems in all countries of the world. While the course was originally developed for delivery in the UK context, the experience of delivering the course in South Africa has demonstrated the commonality of issues in different countries and healthcare environments. Of particular relevance to the development of health services in South Africa were drivers for change such as the demand for consistently high quality services, continuous improvements in health outcomes, cost containment and cost effectiveness. Information and communication technology is considered essential to enable the changes that support high quality clinical work and enhance the cost effectiveness of the health care system. One particular focus of the course has been on managing strategic organisational change $[8,18]$; it is anticipated that the learning and skills gained by students on the course, and especially those working within hospitals and government, will assist them in becoming the kind of leaders needed in healthcare, i.e, people who are able to anticipate and manage such change, incorporating appropriate information and communication technologies. Individuals who have completed the Master's course will be well qualified to create strategies and identify and manage complex projects that focus on facilitating changes in clinical and managerial work through the establishment of an effective 'fit' between the needs of clinical work, the health care system and information and communication technologies.

The MSc in Health Informatics sought to develop the students' research, analytical and organisational skills through their work in nine modules, comprising six taught modules and three independent study modules, culminating in an independent research project, the findings of which are presented in a dissertation. Each taught module followed a similar pattern of delivery over a sixteen week period; there was a pre-reading section, a weeklong taught study block in Mthatha and a consolidation and assessment section supported by a virtual learning environment (VLE) and web sites. Students were expected to study for at least 200 hours a module, and study was through a combination of lectures, seminars and group or personal tutorials with supporting materials available through the VLE. There was an emphasis on active participation, staff-student interaction and student-led discussion. Students were expected to gain the skills of making short presentations and learn from constructive feedback. In addition, students were encouraged to use the VLE discussion list to debate selected issues and use email to keep in touch with their tutors. The Master's course used elearning technology as an educational tool rather than a subject-specific technique for health informatics. It is complementary to traditional Masters teaching methods and supports the development of the enquiring mind in post graduate students and the pace of life in the twenty first century.

\section{Issues and Challenges in Teaching in South Africa}

Delivery of the course commenced in June 2006. Ten students were registered at the University of Winchester and were taught by CHIRAD/University staff who were also teaching a Winches- 
ter-based cohort in parallel; this gave opportunities for shared learning and exchange of experiences and perspectives via video-conferencing and other uses of technology. The cohort of students comprised staff from the Faculty of Family Medicine at Walter Sisulu University, staff from the Eastern Cape Premier's Office, several doctors, one nurse and one IT technician. The following sections, discussing a range of issues and lessons, are based on abridged extracts from a formal evaluation report on the course [2].

\section{Modules/Study Blocks}

The teaching staff made a conscious decision to use a range of teaching and learning methods for two reasons: firstly, to cater for the different learning styles of the students, and secondly, to expose the students to a range of styles that they might use as they transition to become the faculty responsible for delivery of future iterations of the course locally. The intention is that the students will be the teachers of a South African validated MSc in Health Informatics course. There was a mixture of group work, mock lesson preparations and presentations, both individual and group. The students confirmed that they had learned presentation skills and gained in confidence. Both students and staff felt that one of the highlights was the students presenting as a group at an international conference observed by senior South African health informatics government officials and an international audience that included the current IMIA President [20].

Modules tended to evolve, rather than strictly adhering to the timetable, to meet the students' needs. However, despite this, the learning objectives for each module were fully addressed, even though, on occasions, there was a need for rapid adaptation, for example to raise students' level of knowledge, especially on research processes and referencing. Teaching and learning methods also had to change, sometimes at short notice, to adapt to local circum- stances (e.g. power outages, poor Internet access). This highlights the need for experienced and flexible teaching staff who can adapt their methods to these sorts of disruptions.

All the students worked full time, and initially some of them had difficulty being released from work to attend the modules. The Course Director wrote letters to employers detailing when the students needed to be released to attend the study blocks and asking for self study time to be granted to the students. The students felt that having a week study block, rather than isolated days, was very productive and enabled them to concentrate more on studying, especially as they were often set work to do to present later in the block and this required working together during the evenings. Some found the course initially a daunting experience as they only had basic IT skills.

\section{Team Teaching}

All the modules were team taught, with two lecturers in the classroom together much of the time. The team teaching approach allowed total involvement of the team. The benefits included the ability to look to a colleague to reinforce or take up a point if the students seemed not to be grasping the information and to field questions. The students benefited from the diverse and complementary breadth of knowledge between the two staff and the different teaching techniques used, as in any team teaching situation. It was an intense week for two staff, which could have been lonely and isolating if there was only one member of staff, and was exhausting due to the continual attention to the students' needs during the teaching day, even though the two staff took turns in leading sessions.

This is a financially expensive approach to teaching a whole course, but the staff felt that it was probably the best and safest use of the staffing resource at a distance. It enabled the teaching sessions to be interactive; one member of staff could lead a session whilst the other was searching for online resources to illustrate a point. This has additional advantages in not only keeping the teaching resources contemporaneous, but also teaching students how to search for information using the internet, as well as illustrating different teaching techniques.

\section{Guest Speakers, Video Conferencing and Visits}

Guest speakers from the UK and Norway, with specific expertise, taught on several occasions, both face-to-face and through video-conferencing, which added new faces and a different dimension to a module, with the students hearing more than one teacher's view. One of the original plans had been to bring in guests by other forms of Internet conferencing, but the local technical infrastructure (poor speed and reliability for Internet access) meant that this was not possible. One module was taught simultaneously in Mthatha and Winchester; the two groups of students presented to each other and lectures were delivered from both sites through video-conferencing, with email and instant messaging support.

The students made a number of visits in South Africa, e.g. to the Inkosi Albert Luthuli Central paperless hospital in Durban, the regional information office, and the Premier's Office, to illustrate how health informatics is already being implemented in South Africa. The staff also arranged an extracurricular summer school weekend with several speakers from the South Africa Health Informatics Association (SAHIA), who spoke on politics and the realities of health informatics in South Africa. The students also undertook a UK study tour in September 2008 , which was additional to the remit of the course and included attendance at the European Federation for Medical Informatics (EFMI) Special Topic Conference (STC) on "Open Source and Healthcare in Europe Time for Leading Edge Ideas". All of 
these activities were designed to enhance the students' experience, and to expose them to as wide a variety of health informatics expertise as possible; it included the CHIRAD staff drawing on favours from many IMIA colleagues.

\section{Learning Resources and Student Support}

Access to the University of Winchester e-learning environment was initially a problem, mainly due to poor internet connections from South Africa. The staff therefore burned learning resources onto CDs for the students for every module, e.g. folders of PowerPoint, spreadsheets, documents, etc. The students found the CDs useful and often printed off some of the documents pertinent to their assignment and kept others bound in folders or on their hard disk for future use. Access to resources improved during the life time of the course as the internet access in South Africa improved.

The students were supported by the staff both during the blocks and at a distance. One stated that they received more support than if they had been studying a Masters in a South African university. Several commented that they felt they had real support even though Winchester is in the UK. These students may have come from a different cultural background but they had similar family and work issues that UK based mature students have, for example, that they didn't have enough time for assignments because of working full time and family responsibilities.

The authors cannot emphasise enough the personal growth that the MSc course has given to the students, many of whom are now applying what they learned on the course in their own work and teaching. There have also been other direct benefits from undertaking the course, and the skills and knowledge gained; one student has been promoted a number of times to the level of Chief Director of Strategy within the provincial government, while another has been appointed the Clinical Director at the Groote Schuur Hospital, where 40 years ago the first successful human heart transplant was preformed by Professor Christiaan Barnard, and a third has been accepted to undertake a $\mathrm{PhD}$ on completion of the course.

\section{Students' Views}

One of the students provided an extensive description of the experience and benefits derived from the course. In part, she wrote:

the course is relevant to the managers of today as it equips them not only with skills for managing information, but in broad areas of strategy and operations which are critical skills needed today in the government of South Africa. Planning skills in health and education have been rated among priority skills in South Africa, and the MSc modules, in particular Strategy Development, Change Management, and Developments in Information Technology, equip managers with the necessary skills for developing the strategic plan and annual performance plans. The Change Management module imparts the skills needed for implementing new courses and managing change towards improved service delivery in line with the policy implementation context of South Africa. The Developments in Technology module equips the learner with knowledge of IT developments globally, to empower the manager in the decision making processes regarding the choice of health care IT solution, its procurement and implementation. The Masters course does not remove the manager from his/her operational environment which allows him/her on-the-job training opportunities as well.

In commenting further on skills and knowledge gained through the course, the students recognised that, in South Africa, sustainability remains a risk in the development of informatics, and government needs to take this into account in any informatics development initiatives [21]. User buy-in is seen as critical in any system implementation, with lack of user buy-in contributing to the sustainability risk [22], as does lack of user training and lack of understanding of the rationale for system implementation [23]. Experience of management in government has shown that if the service providers or managers at operational level do not understand the strategic direction of the organisation they are less likely to support the implementation, whereas provision of training in health informatics strategy developments and implementation can give managers a much broader perspective.

The students have noted that, while key milestones have been achieved by government, there is still a need for a more coordinated effort in research and development in informatics in South Africa. In the period 1995 to 2002 , South Africa had no national formalized, coordinated and standardised health informatics training and education programme, although some universities have offered informatics as a module in the Masters in Public Health course (MPH) [6]. At both strategic and operational levels in South Africa, there is still a great need for experts in the areas of theories of health information and the social perspective of health information and informatics, health information systems development and principles, health computing science, and electronic patient records [6]. In addition to that, the principles of Accelerated and Shared Growth Initiative for South Africa (AsgiSA) underpin a sense of urgency in developing skills in IT as one of the priority areas, as well as planning in health and education, which call for speciality training [5].

\section{CHIRAD Africa and Future Plans}

At the time of writing this paper, the first cohort of students has reached the 
end of their course, and they are in the process of submitting their MSc dissertations. The next stage of the capacity building is to increase the number of graduates in order to reach a critical mass sufficient to enable a sustainable support system for education programmes. This will be achieved by creating a series of programmes at other universities, in collaboration with those who have undertaken this MSc in Health Informatics.

Although this might sound simple, the process of curriculum development and validation is complex in South Africa, and it moves at a pedestrian rate though the myriad of local and national processes and committees. Whilst the Walter Sisulu University undertakes these tasks it has therefore been proposed that the University of Winchester supports these programmes in terms of validation and award in the first instance.

Three Universities have expressed an interest in starting the MSc Health Informatics as part of this further collaboration, and bids for funding are being developed. The ten graduates from the first cohort have already tasted success in presenting at the HISA conference in Durban [20] and want to support the staff from these universities to understand the various teaching, information and presentation skills they have acquired. Experience in many countries, including the UK, has shown that there is often a need to collaborate with health informatics courses as the number of available expert teachers is scarce.

To aid and encourage health informatics research and development, a not for profit company, CHIRAD South Africa, has been incorporated, with Dr Sedick Isaacs and Brenda Faye from the South Africa Health Informatics Association (SAHIA) as directors. CHIRAD will support the South African national projects and help capacity building by encouraging international collaboration in research and development. It is hoped that by the time of the next MedInfo, in Cape Town in 2010, much of the ground work will be in place, and the momentum afforded by the presence of the Congress will enable
South Africa to take advantage of the opportunities available as a consequence of hosting MedInfo.

\section{Conclusion}

This paper has described the delivery of a Masters of Science in Health Informatics course at Walter Sisulu University, South Africa, covering the rationale and wider context of the course, and a range of issues arising in the delivery and the benefits arising. Despite local logistical problems, some of which may also pertain to other resource challenged parts of the world, the use of skilled and flexible teaching staff, and of a collaborative approach that was based on an appreciation of the local need, resulted in successful delivery. Many benefits have accrued to, and been identified by the student cohort, and lessons learned may be of relevance to other attempts, in South Africa and elsewhere, to develop and sustain local health informatics capacity, to the wider benefit of the health of individuals and populations.

\section{References}

1. Wright G, Betts H, Murray P. Health Informatics Masters Education, Online Learning and Student Support. In: Haux R, Kulikowski C, editors. IMIA Yearbook of Medical Informatics 2005: Ubiquitous Health Care Systems. Schattauer: Stuttgart; 2005.

2. Betts HJ. Evaluation of the Delivery of the MSc Health Informatics Programme at the Walter Sisulu University, Mthatha, South Africa. Unpublished Report for The University of Winchester: Winchester, UK; 2008.

3. Mars M, Seebregts C. Country Case Study for eHealth: South Africa; undated. Available at: http:// ehealth-connection.org/files/resources/County Case Study for eHealth South Africa.pdf

4. Statistics South Africa. Census '96 Overview: Eastern Cape; 1998. Available at: http://www.statssa. gov.za/census $01 /$ census $96 /$ HTML/press/ Part009.html

5. Office of the Premier. Draft White Paper on AsgiSA Eastern Cape (Pty) Ltd. Bhisho: Office of the Premier, Province of the Eastern Cape; 2008. Available at: http://www.ecprov.gov.za/modules/news/rss/ download_media_release.php?id=60

6. Mbananga $\mathrm{N}$. Introduction to Health Informatics. Pretoria: Notoro Publishers; 2006.
7. National Health Information System of South Africa, National Department of Health. The National Strategic Framework for EHR.za Implementation in South Africa; 2007.

8. Berg M. Implementing information systems in health care organizations: myths and challenges. Int J Med Inform 2001; 64:143-56.

9. Lorenzi NM, Ash JS, Einbinder J, McPhee W, Einbinder L. Transforming Health Care Through Information. New York:Springer; 2005.

10. Aarts J, Peel V, Wright G. Organizational Issues in Health Informatics: a Model Approach. Int J Med Inf 1998;52:235-42.

11. Leib B. Mamphela Ramphele, a Biography; undated. Available at: http://www. womeninworldhistory.com/imow-Ramphele.pdf

12. African National Congress. The Reconstruction and Development Programme: a Policy Framework. Johannesburg; 1994 Available at: http://www.anc. org.za/show.php?doc=rdp/rdp.html

13. African National Congress. The National Health Plan for South Africa. Johannesburg; 1994. Available at: http://www.anc.org.za/show.php? doc $=$ ancdocs $/$ policy/health.htm

14. Braa J, Monteiro E, Sahay S. Networks of Action: Sustainable Health Information Systems Across Developing Countries; MIS Quarterly 2004;28:337-62.

15. Williamson L, Stoops N, Heywood A. Developing a District Health Information System in South Africa: A Social Process or Technical Solution? Stud Health Technol Inform 2001;84 Pt 1:773-7.

16. Dept. of Public Service and Administration. The Machinery of Government. Structure and Functions of Government; 2003. Available at: http://www. dpsa.gov.za/documents $/ \mathrm{km} / \mathrm{mog}$.pdf.

17. Braa J, Hedberg C. The Struggle for District-Based Health Information Systems in South Africa. The Information Society 2002;18(2):113-27.

18. Heywood JA et al. District level information systems: two cases from South Africa. Methods Inf Med 1997;36(2):115-21.

19. Lorenzi NM, Riley RT. Managing Change: An Overview. J Am Med Inform Assoc 2000;7:116-24.

20. Students of Walter Sisulu University. A review of the biggest health IT project in the world. Presentation at HISA2008 Conference: Innovations and Challenges in Health Informatics, 2008; Durban, South Africa.

21. Tshayingca-Mashiya NV. Application of risk management in implantation of eHealth Strategies;2008. Unpublished dissertation.

22. Heeks R. Health information systems: failure, success and improvisation. Int J Med Inform 2006; 75:125-37.

23. Littlejohns P, Wyatt J, Garvican L. Evaluating computerised health information systems: hard lessons still to be learnt. BMJ 2003;326:860-3.

Correspondence to:

Dr. Peter J. Murray

Director and Founding Fellow, CHIRAD

Coachman's Cottage

Nocton Hall, Nocton

Lincoln, United Kingdom

E-mail: peterimurray@gmail.com

www.chirad.org 